\title{
BMJ Open Technical and scale efficiency of provincial health systems in China: a bootstrapping data envelopment analysis
}

\author{
Peipei Chai, ${ }^{1,2}$ Yuhui Zhang, ${ }^{2}$ Maigeng Zhou, ${ }^{3}$ Shiwei Liu, ${ }^{3}$ Yohannes Kinfu ${ }^{1,4}$
}

To cite: Chai P, Zhang $Y$, Zhou M, et al. Technical and scale efficiency of provincial health systems in China: a bootstrapping data envelopment analysis. BMJ Open 2019;9:e027539. doi:10.1136/ bmjopen-2018-027539

- Prepublication history for this paper is available online. To view these files, please visit the journal online (http://dx.doi. org/10.1136/bmjopen-2018027539).

Received 27 October 2018 Revised 12 June 2019 Accepted 05 July 2019

A Check for updates

(c) Author(s) (or their employer(s)) 2019. Re-use permitted under CC BY-NC. No commercial re-use. See rights and permissions. Published by BMJ.

${ }^{1}$ Faculty of Health, University of Canberra, Canberra, Australian Capital Territory, Australia

${ }^{2}$ National Health Accounts and Policy Studies, China National Health Development Research Center, Beijing, China ${ }^{3}$ National Center for Chronic and Non-communicable Disease Control and Prevention, Chinese Center for Disease Control and Prevention, Beijing, China ${ }^{4}$ Department of Health Metrics Sciences, University of Washington, Seattle, Washington, USA

Correspondence to

Peipei Chai;

peipei.chai@canberra.edu.au

\section{ABSTRACT}

Objective With escalating health expenditures and increasing health needs, improving health system performance has become imperative in China and internationally. The objective of this study is to examine the efficiency of China's health system and to understand the underlying causes of the variation in efficiency across provinces.

Setting A system-wide perspective is adopted, focusing on performance in maternal health, child health and noncommunicable diseases (NCDs) in the 31 provinces of mainland China during 2015.

Methods Analyses were performed using bootstrapping data envelopment technique. Health outcomes were measured by infant survival rates, maternal survival rates and healthy life years calculated only considering NCDs. Health inputs were measured using health expenditure, and density of medical personnel and hospital beds. The model also examined the impact of environmental factors on health system efficiency.

Results Due to wide-spread scale inefficiency in the country, the average bias-corrected overall technical efficiency (OTE) was 0.8022 (95\% $\mathrm{Cl}$ values ranging from 0.7251 to 0.8492 ). Socioeconomic status, hospitalisation rate and share of out-of-pocket expenditures were significant determinants of OTE. Nearly $60 \%$ of the provinces operated at a decreasing return to scale, meaning that a gain in efficiency could be achieved only through downsizing the scale of operation.

Conclusions Given the pervasive nature of diminishing returns across provinces, health policy makers must explore the optimum operational scale which is peoplecentred and focused on prevention, rather than on treatment, of diseases. Moreover, due consideration should be afforded to social determinants of health and health financing arrangements to complement health-sector based reforms and meet the ambitious goals of the Healthy China 2030 Plan.

\section{INTRODUCTION}

Health is a basic human right as well as a precondition for the economic and social development of nations. ${ }^{12}$ As an important national strategic plan for the health sector, the Healthy China 2030 Plan launched in 2016 aims to achieve a series of goals in
Strengths and limitations of this study

- Composite health outcomes consisting of maternal health, child health and non-communicable diseases were used to measure health system outputs in this study.

- A bootstrapping method was used to correct the biased efficiency scores obtained by the traditional data envelopment analysis models.

- The study only focuses on cross-sectional data and cannot reflect the change in technical efficiency over healthcare reform periods.

- Given the great variation within each province, further analysis at a lower level of geography (ie, the county level) is also necessary.

five areas, with an emphasis on improving maternal and child health and reducing premature mortality due to non-communicable diseases (NCDs). ${ }^{3}$ However, achieving these ambitious goals will not be easy, given the massive challenges within and beyond the health system. First, on the demand side, factors such as rapid population ageing, rising burden of NCDs, increasing prevalence of risk factors and changes in environmental factors will continue to put pressure on the country's health system as it tries to transform itself and meet the 2030 Healthy China agenda. ${ }^{1}$ These increasing health needs indicate that China will struggle to meet the demands for increased health spending. Since 2008, health expenditures in China have grown, on average, by $12.8 \%$ per year, a rate substantially higher than the growth in $\mathrm{GDP}^{4}$; however, to what extent this trend will continue into the future remains to be seen, especially as China's economy becomes more mature and the growth rate slows down in the coming decades. ${ }^{56}$ In addition, on the supply side, changing medical practices, the legacy of uneven distribution of resources and wide disparities in population health across China 
will continue to pose enormous challenge to the nation. For example, a newly born child in Beijing can expect to live an average of 83.5 years in 2015 ; however, this value is approximately 10 years longer than the life expectancy for a child born in Tibet. ${ }^{7}$ However, such health gaps between provinces seem unlikely to be narrowed by solely increasing health inputs because in places like Tibet total health expenditure as percentage of the province's GDP is already among the highest in the country, that is, $10 \%{ }^{4}$

Globally, it is estimated that $20 \%-40 \%$ of health expenditures could be saved without producing adverse health outcomes. ${ }^{8}$ The need for containing rising cost of healthcare vis-à-vis increasing health needs of populations in places like China and elsewhere means that improving health system efficiency has become a centre of attention across countries. However, despite the focus and priority accorded to achieving value for money in the country's health sector reform agenda, to-date there is limited evidence on health system performance assessment in China. Most of the available literature do not accurately or effectively capture the efficiency of the health system as a whole because they are largely focused on assessing institutional level technical efficiency. ${ }^{9} \mathrm{~A}$ few studies that examined technical efficiency at a system level, on the other hand, use healthcare activities such as outpatient visits and number of hospital admissions rather than health outcomes per se. ${ }^{10}$ However, such an approach has several limitations. First, in the Chinese context, an activity-based analysis is clearly restrictive, biased and of limited use in guiding policies and decision-making. This is partly to do with the existence of a distorted health pricing system in China, which encourages health providers to over-treat patients, and overuse drugs, tests and treatment. Moreover, an activity-based system sacrifices quality of care and leads to burnout of medical staff, and patient dissatisfaction, all of which could cause increased disputes between patients and doctors. ${ }^{11-13}$ In addition, an activity-based efficiency analysis also goes against the two core aspects of the country's health reform agenda, namely achieving value for money and shifting the focus away from the production of treatments to producing better health for the population. ${ }^{56}$ Several studies have used alternative health outcome-based measures, such as life expectancy, maternal mortality rate (MMR) and infant mortality rate (IMR), as their outputs of interest. ${ }^{14-16}$ However, these studies are outdated and use a limited range of input variables and external factors that affect the efficiency of health system in the country. Moreover, all of these studies had focused on a single outcome, but focusing solely on one outcome (such IMR or MMR), as was done in these studies, fails to capture the broader roles that the health system plays beyond maternal and child health, such as in the prevention and control of NCDs.

The objectives of this study are, therefore, to examine technical efficiency from a holistic system-wide perspective with a focus on the improvement of child health, maternal health and NCD-related health conditions and to understand the drivers of the variation in technical efficiency across provinces. This will help determine where the Chinese health system is doing well and where it is falling short and in turn generate a body of evidence that will guarantee the achievement of the country's 2030 Health agenda with greater efficiency.

\section{METHODOLOGY}

Traditionally, technical efficiency is measured using two major methodological approaches: parametric and non-parametric. In the case of the former, the most prominent method is stochastic frontier analysis (SFA), while data envelopment analysis (DEA) is the most common approach in the latter category. SFA allows to estimate efficiency levels and identify effects of the decision-making unit's (DMU) characteristics on efficiency scores, but it requires a functional form (or a distribution) to be imposed in the analysis. ${ }^{17}$ DEA requires no distributional assumptions. It also allows for multiple outputs and is more flexible regarding the number of DMUs required for analysis. ${ }^{18-20}$ Taking these advantages into account, a DEA approach was adopted in this study.

\section{Data envelopment analysis}

DEA is a linear programming mechanism used to estimate the efficiency of DMUs. The CCR model developed by Charnes, Cooper and Rhodes (CCR model) ${ }^{20}$ and the BCC model developed by Banker, Charnes and Cooper (BCC model $)^{21}$ are the two extensively used models within the DEA framework. Technical efficiency scores obtained using the CCR model represent overall technical efficiency (OTE). These scores can be decomposed into pure technical efficiency (PTE) and scale efficiency (SE) using the BBC model as expressed in the following equation. ${ }^{21}$

\section{OTE=PTE $\times$ SE}

Output orientation and returns to scale

A DEA model can be either input-oriented or output-oriented. Under input orientation, the efficiency scores correspond to the largest feasible proportional reduction in inputs for given outputs; under output orientation, the efficiency scores correspond to the largest feasible proportional expansion in outputs for given inputs. ${ }^{20} \mathrm{In}$ this study, an output-oriented model was adopted due to the desirability of maximising health outcomes given that input levels in the health system are usually fixed in the short run. ${ }^{22} 23$

Returns to scale (RTS) is an important concept in production function as it explains long-run relationships between inputs and outputs. The CCR model operates under the assumption of constant return to scale (CRS), which implies that a unit increase in input levels will result in a proportional increase in outputs. If the global technology is not operating under a CRS, technical efficiency levels estimated using a CRS model are generally inconsistent. A variable return to scale (VRS) model, developed as part of the BBC, addresses this shortcoming by allowing 
a disproportionate change in output levels as input levels change by one unit. Accordingly, an increasing return to scale is achieved when greater increases in the outputs are attained, while a decreasing return to scale (DRS) is achieved when a unit change in input leads to a disproportionately lower increase in the output level. Hence, given the importance of global technology in the DEA and the absence of solid evidence on the nature of RTS in this study area, a two-part returns-to-scale test as proposed by Simar and Wilson ${ }^{24}$ was performed.

According to the result of the test, the null hypothesis of CRS was rejected at a 99\% level of significance. Therefore, a VRS was used to assess the performance of different provincial health systems in the promotion of health.

\section{Bootstrapping DEA and truncated bootstrapped regression}

Traditional DEA models are more sensitive to the selection of inputs and outputs and neglect the effects of non-discretionary factors that influence the production function, which make the efficiency scores biased. Hence, a bootstrapping DEA model proposed by Simar and Wilson was used to estimate bias-corrected technical efficiency scores at the first stage. A truncated bootstrapped regression was used in the second stage to identify external factors that may influence the efficiency scores. The analyses were performed in Stata V.15 using user-developed commands proposed by Badunenko and Mozharovskyi. ${ }^{25}{ }^{26}$ Based on the default settings, 1000 repetitions and 2000 repetitions had been used in the first and second stage analysis, respectively.

\section{Patient and public involvement}

Our analysis was based on publicly available aggregated secondary data. Hence, the study did not directly involve patients or the public at large.

\section{Data and variables}

\section{Input and output variables}

The Chinese health system is made up of a hybrid system, whereby both private and public delivery of health services and healthcare payment systems coexist. There are mainly two health insurance systems in operation in China: the medical insurance scheme designed for urban employees and the system available for rural residents and those who are not in the labour force. The latter includes children and the elderly in urban areas as well as rural residents who are covered through the new rural cooperative medical schemes. Both schemes operate throughout the country and are similar across the provincial health system.

To examine health system efficiency at the provincial level, we have included all the 31 administrative areas in mainland China. These provinces form the DMUs in our analysis. Variables for analysis were selected based on evidence from similar previous studies and availability of data. ${ }^{27-30}$ For the input portion, the number of medical personnel per 1000 residents, the number of hospital beds per 1000 residents and the total health expenditure per capita was used. Medical professional category includes physicians (namely general practitioners and specialists), but does not include nurses, pharmacists or other medical staff. It is recognised that physical measures such as the number of equivalent full-time staff may be a better indicator of availability of human resources for health, but unfortunately such data are not available. Hospital bed was used as a proxy for capital investment. Total health expenditure per capita is the sum of public and private health expenditure as a ratio of total population, and it covers the spending on all kinds of health providers for health service delivery.

For the output portion, the health outcomes were measured by IMR, MMR, and the mortality and the years lost due to disability (YLD) caused by NCDs, in view of several reasons. First, each measure basically represents the health status of three key population groups that can benefit from effective health systems. It is reported that premature mortality from NCDs by 2030 can be reduced by one-third if more effort is committed and certain targets for risk factor interventions are achieved in China. ${ }^{31}$ Two-thirds of the avoidable maternal and infant mortalities were attributed to health worker-related factors, and $10.2 \%$ were attributed to poor supply factors. ${ }^{32}$ The main causes of maternal mortality are all amenable to interventions at a health system level and are highly relevant in China. ${ }^{33} 34$ Second, these conditions represent major public health concerns in China. NCDs are responsible for $87 \%$ of total deaths in China ${ }^{31}$, and significant health gaps still exist in child health and maternal health across provinces. Additionally, all three indicators represent major areas of focus in the Healthy China 2030 Plan and are of high policy significance.

In the DEA model, outputs are understood to represent 'more is better'. To meet these criteria, as what had been done in previous studies, ${ }^{27}{ }^{30}$ IMR was converted into infant survival rates (ISR) (ISR=1000-IMR), and MMR was converted into maternal survival rates (MSR) (MSR=100000-MMR). NCDs mortality and YLD was converted into NCDs-based healthy life years (HLY NCDs), whereas only mortality and morbidity caused by NCDs were considered when calculating HLY. The concept of HLY has emerged as one of the more commonly used health status measures that incorporates both mortality and morbidity. ${ }^{35} 36$

Factors such as disposable income per capita, educational attainment, urbanisation rate, financing protection (represented by the percentage of out-of-pocket (OOP) in total health expenditure) and healthcare service use pattern measured by admission rate were considered in the second stage analysis. These factors were selected based on evidence from similar previous studies and availability of data. ${ }^{27-30}{ }^{37}$ Given only 31 observations in our analysis, to keep a limited number of independent variables in the analysis, a composite socioeconomic status (SES) index was constructed using principal component analysis based on disposable income per capita, educational attainment and urbanisation. 


\begin{tabular}{|c|c|c|c|c|c|}
\hline Variable & Units & Mean & SD & Minimum & Maximum \\
\hline \multicolumn{6}{|l|}{ Outputs } \\
\hline ISR & Per 1000 live births & 994.69 & 3.36 & 984.00 & 997.77 \\
\hline MSR & Per 100000 live births & 99983.68 & 17.52 & 99899.10 & 99997.70 \\
\hline HLY_NCDs & Years & 77.25 & 2.50 & 71.86 & 82.93 \\
\hline \multicolumn{6}{|l|}{ Inputs } \\
\hline Health expenditure & CNY per capita & 3258.34 & 1297.42 & 2103.71 & 8453.14 \\
\hline Medical personnel & Per 1000 residents & 2.25 & 0.42 & 1.70 & 3.90 \\
\hline Hospital bed & Per 1000 residents & 5.13 & 0.63 & 4.02 & 6.37 \\
\hline \multicolumn{6}{|l|}{ Environmental variables } \\
\hline Disposable income & CNY per capita & 21912.26 & 8988.54 & 12254.30 & 49867.20 \\
\hline Urbanisation & Percentage & 56.64 & 12.89 & 27.74 & 87.60 \\
\hline Education attainment & Years & 8.59 & 1.34 & 4.17 & 12.16 \\
\hline $\begin{array}{l}\text { Percentage of OOP in total health } \\
\text { expenditure }\end{array}$ & Percentage & 29.00 & 6.49 & 5.71 & 36.89 \\
\hline Admission rate & Percentage & 14.43 & 3.00 & 7.30 & 21.40 \\
\hline
\end{tabular}

ISR, infant survival rates; MSR, maternal survival rates; HLY_NCDs, NCDs-based healthy life years; OOP, out-of-pocket.

\section{Data source}

Multiple data sources were employed. The data source of each variable is listed as follows.

- China Health and Family Planning Statistical Yearbook 2016: MMR, medical personnel density, hospital bed density.

- China Maternal and Child Annual Health Report: IMR.

- National Health Reports 2016: Health expenditure per capita, percentage of OOP in total health expenditure.

- Chinese Center of Disease Control and Prevention: NCDs mortality and YLD.

- China Statistical Yearbook 2016: disposable income per capita, educational level, urbanisation rate and admission rate.

\section{RESULTS}

\section{Descriptive statistics}

Table 1 presents a descriptive overview of the variables used in this study. The ranges for inputs and outputs are quite wide. For example, the ISR across provinces vary between 984 per 1000 live births and 998 per 1000 live births, namely, a baby's risk of death in the first year of life in Tibet is nearly six times greater than that in Guangdong and Beijing. Regarding the HLY_NCDs, an 11.07year gap exists between provinces. The lowest was Tibet (71.86 years) and the highest was Shanghai (82.93 years). Similar patterns are apparent for inputs, especially health expenditures. The health expenditure per capita ranged from 2103.71 Chinese Yuan (CNY) to 8453.14 CNY, which suggests that the level of health system input is quite heterogeneous across provinces.

\section{Efficiency estimates}

Table 2 summarises the bias-corrected OTE, PTE and SE estimates obtained using an output-oriented DEA model for the 31 provinces of China. As mentioned earlier, the estimates were generated using VRS technology following results of RTS test. The bias-corrected PTE for the country as a whole was 0.9947, meaning that overall the country's health system has been operating highly efficiently. The mean level of $\mathrm{SE}$ is, however, much lower, that is, approximately 0.8653 (suggesting scale inefficiency level of $13.47 \%$ ). As a consequence, the bias-corrected OTE was 0.8022 (95\% CI 0.7251 to 0.8492 ).

Table 2 further suggests that only 13 of the 31 provinces (or $41.9 \%$ of the total) operated at the most productive scale size (MPSS). The remaining 18 provinces $(58.1 \%)$ operated at a DRS which means that a gain in efficiency can only be achieved by scaling down operational size.

Figure 1 portrays a deeply heterogeneous picture in terms of bias-corrected OTE across 31 provinces. It clearly shows five tiers in technical efficiency levels by geographic locations. Tianjin, Guangdong and Hainan in the east, and Yunnan and Tibet in the west had the highest biased-corrected OTE values, ranging from 0.9186 to 0.9486, whereas Inner Mongolia, Sichuan, Qinghai and Xinjiang in western China had the lowest biased-corrected OTE, ranging from 0.6441 to 0.7458 , along with Liaoning, Heilongjiang, Shandong and Hubei. Regions of high level economic development, such as Beijing, Shanghai, Zhejiang and Jiangsu, do not rank high in biased-corrected OTE, yielding values of lower than 0.80, which indicates the high level of scale inefficiency. The Kruskal-Wallis test confirmed that the biased corrected 


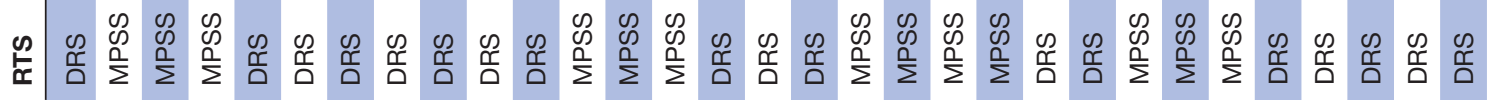

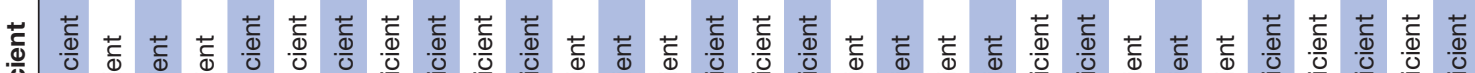

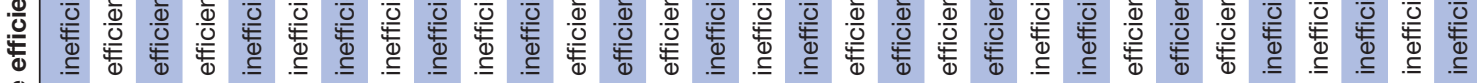

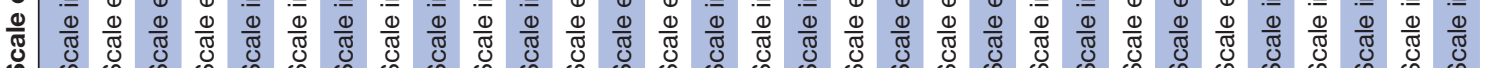
告

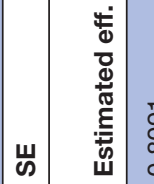

象

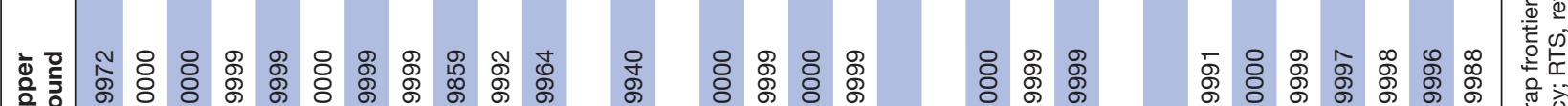

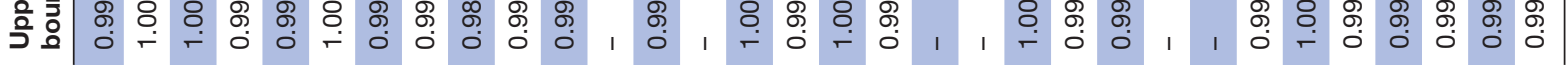

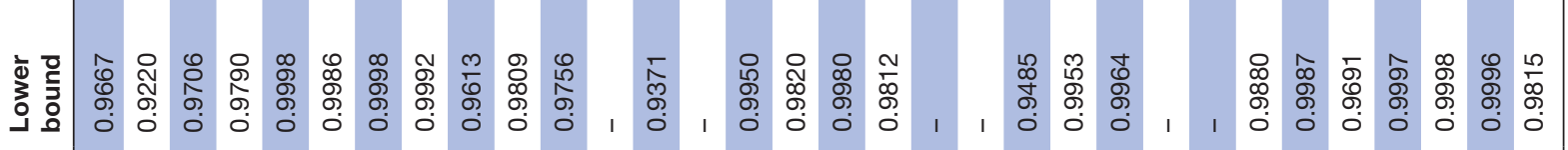

焉

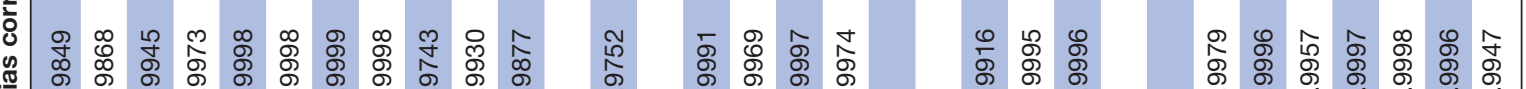

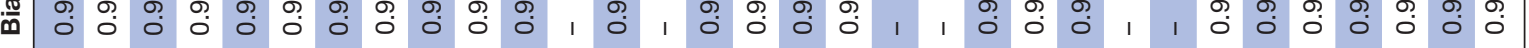

它

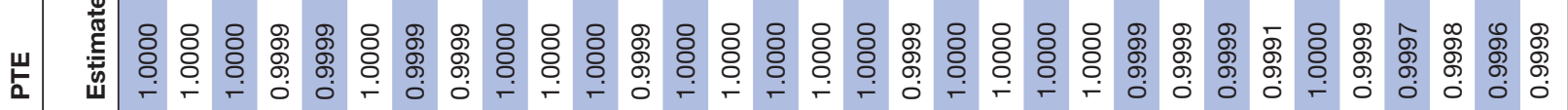

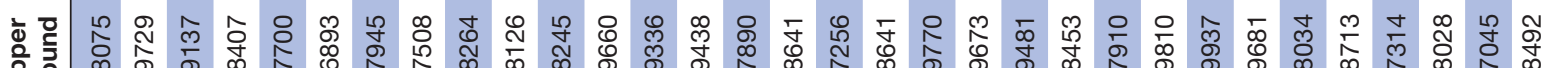

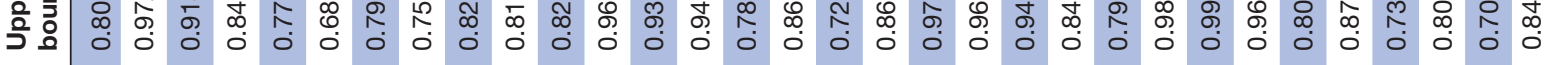

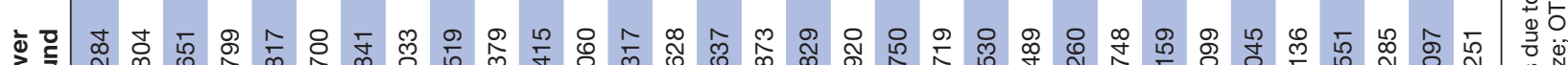

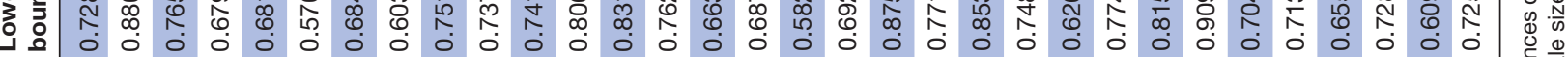

ठ

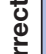

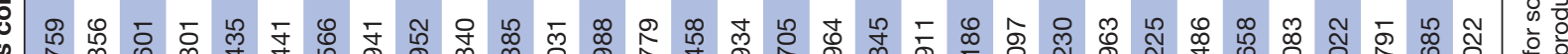

品

m

递

$\frac{0}{8} \sum^{\infty}$

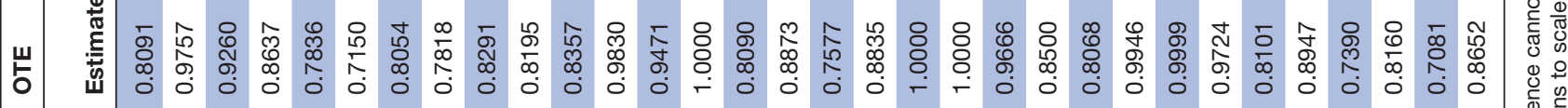

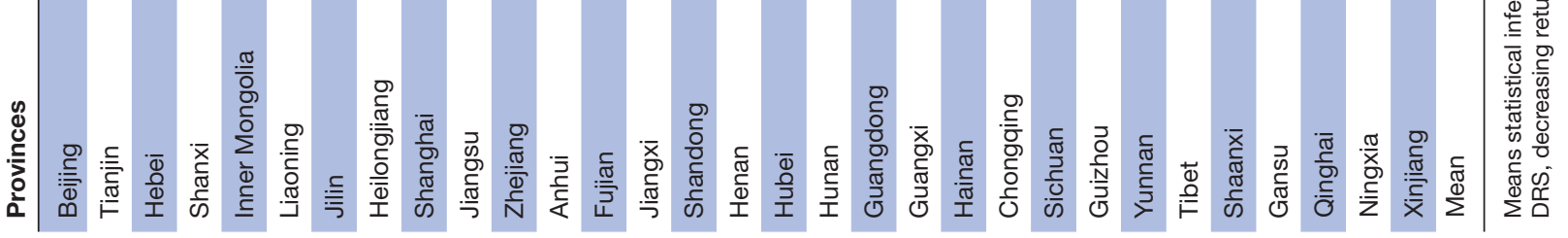




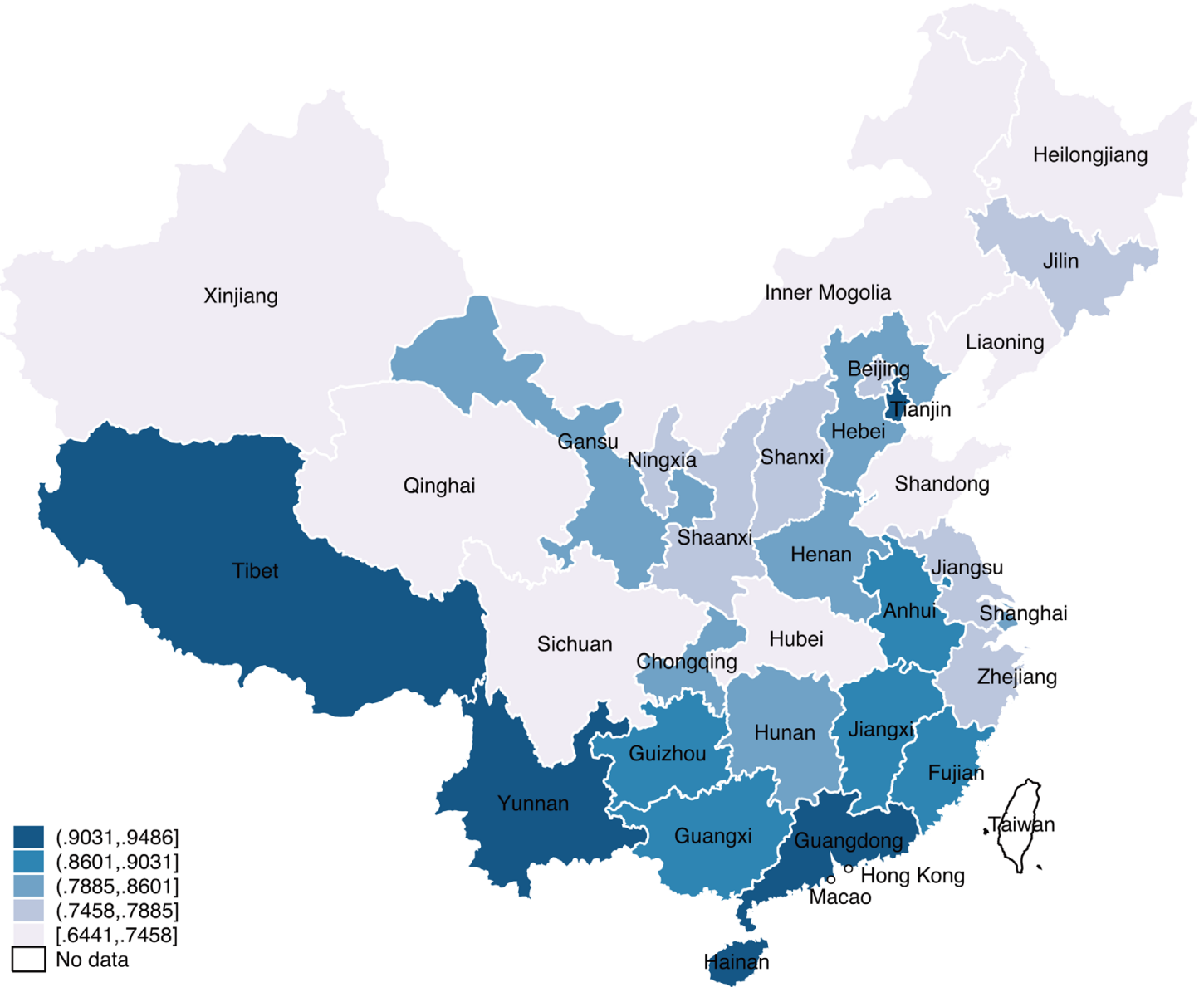

Figure 1 Overall technical efficiency across provinces.

OTE scores differe but not significantly among groups, and biased corrected PTE scores significantly differ among groups based on their location $(\mathrm{p}<0.10$ for OTE, and $\mathrm{p}<0.001$ for PTE). Generally, the provinces located in the east outperformed all other regions, with a mean biased corrected OTE of 0.8380 , followed by those in the west and in the centre. North-eastern provinces performed the worst. In contrast, eastern provinces were the least efficient in PTE, but the gap was negligible.

Figure 2 portrays the association between SE and health inputs. Accordingly, the most scale efficient provinces tend to have lower health worker and hospital bed densities. The means of the number of medical personnel and hospital beds between scale efficient provinces and scale inefficient provinces were significantly different $(\mathrm{p}<0.001)$.

Table 3 presents the results of the truncated bootstrapped regression analysis, which estimated the effect of environmental factors on OTE at the provincial level. The results suggest that OTE levels were negatively and significantly affected by SES index, percentage of OOP in total health expenditure and hospital admission rate.

\section{DISCUSSION}

This study investigated TE and SE of the provincial health system in China and the role of environmental factors in influencing both SE and PTE with respect to ISR, MSR and HLY_NCDs. The work is of particular policy significance given the finite health resources and continually rising health needs.

Our results indicate that bias-corrected PTE was generally high in all provinces (ie, 0.9947). However, given the relatively high levels of scale inefficiency (ie, 13.47\%), the bias-corrected OTE level, on average, was rather low (ie, 0.8022). Moreover, the OTE was quite heterogeneous across provinces. Provinces in the high economic development corridor in the eastern China tended to have a relatively high OTE, while provinces in the less-developed regions performed less efficiently, especially the northeastern provinces, which displayed the lowest OTE. Some of the well-off provinces also experienced high inefficiency in their local health systems. For example, Beijing, Shanghai, Jiangsu and Zhejiang scored bias-corrected OTE values of less than 0.80 , which meant that considerable resources invested in these regions did not generate the desired impact on health outcomes. Nevertheless, of even greater concern was that less-developed provinces with poor health outcomes, such as Xinjiang, Heilongjiang and Qinghai also suffered poor OTE in the production of health.

In our study, the low OTE of health systems across provinces was generally caused by a high level of scale inefficiency 


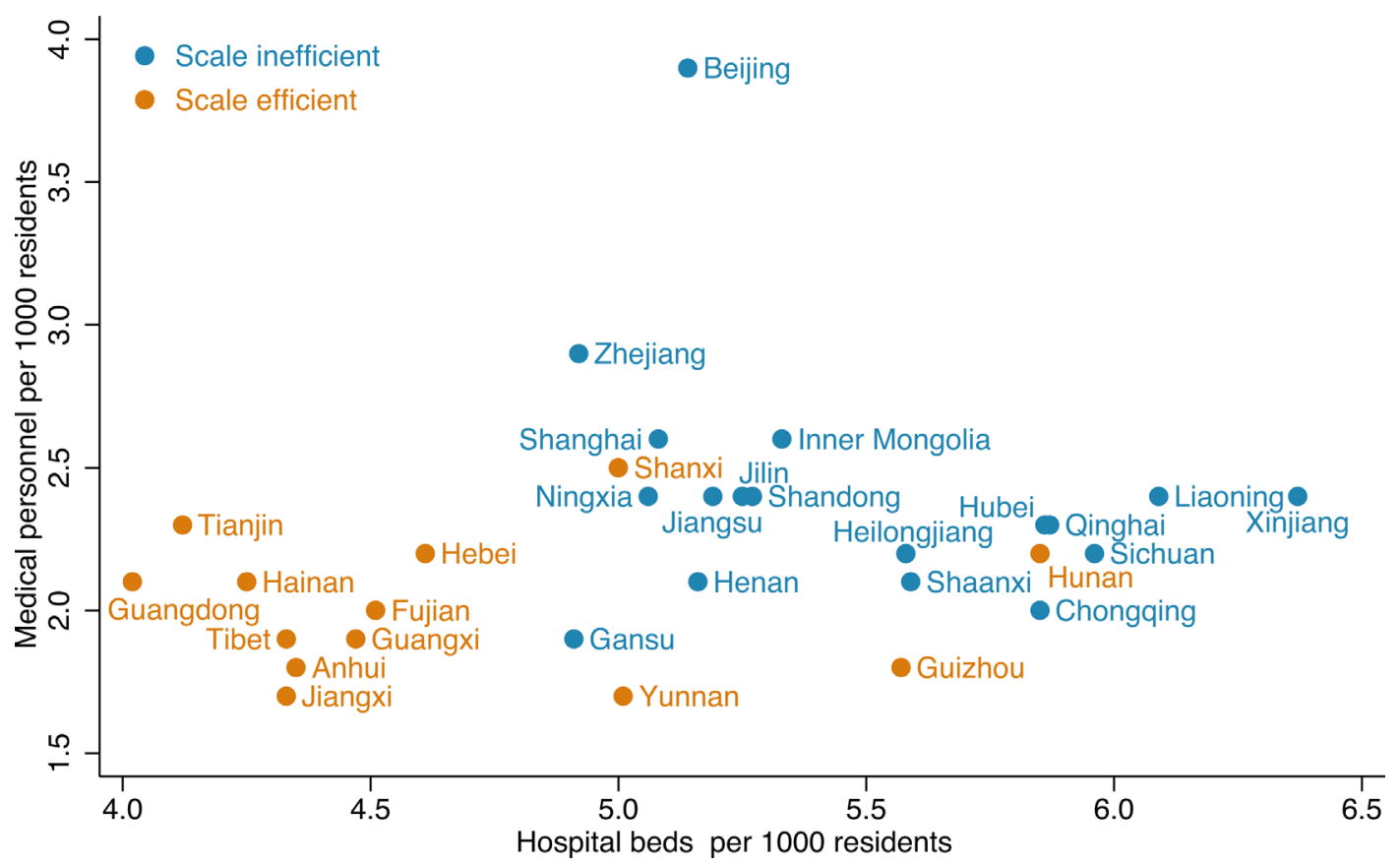

Figure 2 Association between scale efficiency and health inputs.

observed across provinces. The results indicated only $41.9 \%$ of the provinces operated at the MPSS, while $58.1 \%$ exhibited DRS, which implied that an increase in inputs can only generate a smaller increase in health outcomes. In general, hospital bed density played an important role in the SE of provinces. If the hospital bed density was greater than 5.0 per 1000 residents, the chances for a province to be scale inefficient were greater. This reflected the so-called flatof-the-curve medicine phenomenon, referring to a level of intensity of care that provides no incremental health benefit. ${ }^{38}$ Coincidentally, an increasing number of studies have shown diminishing returns of health system inputs on health outcomes. For instance, Asandului et al revealed that 26 of 30 European countries under scrutiny exhibited DRS, and only four countries presented a scale efficient system. ${ }^{39}$ Cetin and Bahce reported that technical efficiency would be increased by using lower resources for 11 OECD countries with health systems characterised by DRS. ${ }^{40}$ Another study showed that reducing health input levels can help improve efficiency in Central Asian health systems. ${ }^{41}$ This also holds in the case of China. Zhang et al revealed that the reduction of SE is an objective law when they investigated health system efficiency in China as a whole compared with other countries. ${ }^{10}$

Variables for analysis were selected based on evidence from similar previous studies and availability of data. Given the heterogeneous OTE of health systems across provinces in China, Simar and Wilson's two-stage procedure was employed to examine and better understand the drivers behind this variation. ${ }^{24}$ Several findings are highlighted here. First, the results suggested that the higher the percentage of OOP in total health expenditures is, the greater the inefficiency level is, which implies that a public financing-dominated care system is more suited to create a more efficient production of health. Consistent with the findings of González et $a l^{42}$ they reported that the public share in health expenditures is positively associated with improved health system performance. Sun $e t$ al found a $1 \%$ point increase of the share of social security spending could improve health system efficiency by $1.9 \%{ }^{43}$ It is intuitive because a public financing arrangement entails people having equal access to health services and improves their utilisation of health resources that have already been equipped. In recent years, the Chinese

Table 3 The effects of the environmental variables on overall technical efficiency

\begin{tabular}{|c|c|c|c|c|c|}
\hline & Observed coef. & Bootstrap std. err. & $P>z$ & \multicolumn{2}{|c|}{ Percentile $(95 \% \mathrm{Cl})$} \\
\hline Socialeconomic status index & -0.004 & 0.002 & 0.005 & -0.007 & -0.002 \\
\hline Percentage of OOP in total health expenditure & -0.007 & 0.003 & 0.035 & -0.013 & -0.001 \\
\hline Constant & 1.494 & 0.213 & $<0.001$ & 1.154 & 1.947 \\
\hline
\end{tabular}

Wald $\chi^{2}(10)=10.42$, Prob $>\chi^{2}(10)=0.0153$.

OOP, out-of-pocket. 
government has acknowledged that the current financial risk is high in China, and further efforts to improve public financing have been stressed. According to the Healthy China 2030 Plan, the percentage of OOP in total health expenditures is planned to be reduced from $29 \%$ in 2015 to $25 \%$ by $2030 .{ }^{3}$

Second, in our study, the negative association of admission rates with efficiency implied that a resource-intensive hospitalisation service use was harmful to health system efficiency. Our results are similar to those of Chowdhury and Zelenyuk which reported that outpatient-inpatient ratio is a significant driver of efficiency. ${ }^{37}$ If limited health resources are not rationally allocated and used to maximise health outcomes, low technical efficiency would occur. In China, over the past 37 years, that is, since the 'opening-up policy', total health expenditures have been rapidly growing, with an annual growth rate of $11.7 \% .^{4}$ One underlying cause of the unprecedented escalation of health expenditures is a rapidly expanding public hospital system, with hospital beds being a major component. Hospitals account for $54 \%$ of China's total health expenditures, ${ }^{4}$ which was more than the OECD average level of $38 \%{ }^{44}$ As the saying goes, 'A hospital bed built is a bed filled'. ${ }^{45}$ Accordingly, the number of hospital beds in China doubled from 1.2 million to 2.2 million from 1980 and 2000, and reached 5.3 million in $2015 .{ }^{46}$ Currently, the Chinese health delivery system features a highly hospital-centred care system with a primary health system that is marginalised as well as fragmented. ${ }^{47}$ The level of hospital bed density in China now exceeds some OECD countries such as Canada, the UK, the USA and Spain. ${ }^{44}$

SES is one of the most powerful predictors of health indicator, and addressing several components of SES (ie, income poverty and low education) could be important for population health improvement. ${ }^{49}$ In our study, we observed that provincial health system inefficiency was positively associated with provincial socioeconomic index. The results of curret study were inconsistent with that of Ramin et al, Achoko et al and de Cos and MoralBenito. ${ }^{28-30}$ In terms of maternal and child health, many studies have documented that maternal literacy plays a crucial role in improving life-saving services for mothers and children. ${ }^{50}{ }^{51}$ Moreover, it has been proved in many studies that economic level (eg, per capita GDP) was positively associated with health system efficiency. ${ }^{29} 52$ However, the effect of urbanisation on health is not clear-cut in China. While urban life offers individuals the benefits of access to improved healthcare, nutrition and sanitation facilities, it also exposes them to air pollution, risk of traffic hazards and behavioural risks associated with changing diets and physical activity patterns. ${ }^{53}$

Finally, given the high level of scale inefficiency in China, it is imperative for health policy-makers to explore the optimum operation scale of health systems and rationalise health systems' supplies, rather than blindly increase health resource investment to achieve better population health. It is well known that health could be greatly improved by reallocating resources from interventions that are not cost-effective to those that are more cost-effective but not fully implemented for health systems. ${ }^{22} 3842$

\section{Limitations and suggestions for future research}

Our analysis is not without limitations. First, it focused only on health system efficiency using cross-sectional data. Future research can use multiple data points and examine how efficiency has changed in the country over time, especially examining the impact of healthcare reforms on health system efficiency and productivity. Second, we have only looked at health system efficiency at a provincial level, mainly due to data limitations. However, further analysis focusing on the county level is also necessary given variations in health inputs and outputs within each province. Third, in our analysis the primary DMUs (ie, provinces) are assumed to be independent of each other, which may not be the case. Hence, a spatially sensitive efficiency model, such as those developed for SFA, ${ }^{54}$ can be considered in future studies.

\section{CONCLUSIONS}

Improving health system efficiency is crucial for achieving value for money and improving population health across China and internationally. Given the pervasive diminishing returns in health systems across China, health policy-makers must shift the focus on treating people to preventing diseases, and exploring the optimum operation which ensures that resource allocation is people-centred. Moreover, social determinants of health and health financing arrangements should also be fully considered and a target for policy-makers to realise the ambitious goals of the Healthy China 2030 Plan.

Acknowledgements The authors are very thankful to John Goss, Jinjing Li and Itismita Mohanty for their useful comments and suggestions. They also would like to thank the reviewers for their helpful remarks and suggestions. American Journal Experts, a professional copyediting agency, helped to further refine the manuscript.

Contributors PC and YK conceived the study; PC contributed to the analysis and interpretation of the data; $\mathrm{YZ}, \mathrm{MZ}$ and SL contributed to the data acquisition and provided statistical analysis support; and PC and YK drafted the article. All authors supplied critical revisions to the manuscript and gave final approval of the version to be published.

Funding The authors have not declared a specific grant for this research from any funding agency in the public, commercial or not-for-profit sectors.

Map disclaimer The depiction of boundaries on the map(s) in this article do not imply the expression of any opinion whatsoever on the part of BMJ (or any member of its group) concerning the legal status of any country, territory, jurisdiction or area or of its authorities. The map(s) are provided without any warranty of any kind, either express or implied.

Competing interests None declared.

Patient consent for publication Not required.

Provenance and peer review Not commissioned; externally peer reviewed.

Data availability statement No additional data are available.

Open access This is an open access article distributed in accordance with the Creative Commons Attribution Non Commercial (CC BY-NC 4.0) license, which permits others to distribute, remix, adapt, build upon this work non-commercially, and license their derivative works on different terms, provided the original work is 
properly cited, appropriate credit is given, any changes made indicated, and the use is non-commercial. See: http://creativecommons.org/licenses/by-nc/4.0/.

\section{REFERENCES}

1. Fu W, Zhao S, Zhang Y, et al. Research in health policy making in China: out-of-pocket payments in healthy China 2030. BMJ 2018;360

2. [Xi Jinping: Put people's health in a priority development strategy] [Chinese]. Xinhua News Agency 2016;20.

3. Xinhua News Agency. [Healthy China 2030, 2016. Available: http:// news.xinhuanet

4. China National Health Development Research Center. China National health accounts report: CNHDRC 2017.

5. Bank W. The development research center of the state Council P. R. China. China 2030: building a modern, harmonious, and creative Society. Washington, DC: World Bank, 2013.

6. World Bank Group, World Health Organization, Ministry of Finance. Deepening health reform in China building high-quality and valuebased service delivery 2016.

7. Zhou M, Li Y, Wang H, et al. Analysis on life expectancy and healthy life expectancy in China, 1990-2015. Chinese journal of Epidemiology 2016;37.

8. Chisholm D, Evans DB. Improving health system efficiency as a means of moving towards universal coverage. World health report, 2010.

9. Cylus J, Papanicolas I, Smith PC. Using data envelopment analysis to address the challenges of comparing health system efficiency. Glob Policy 2017;8:60-8.

10. Zhang L, Cheng G, Song S, et al. Efficiency performance of China's health care delivery system. Int J Health Plann Manage 2017;32:254-63.

11. Chen X, Tan X, Li L. Health problem and occupational stress among Chinese doctors. Chin Med 2013;04:1-6.

12. He AJ, Qian J. Explaining medical disputes in Chinese public hospitals: the doctor-patient relationship and its implications for health policy reforms. Health Econ Policy Law 2016;11:359-78.

13. Yip W, Hsiao W. China's health care reform: a tentative assessment. China Economic Review 2009;20:613-9.

14. Li X, Li D, Huang $L$. The health production efficiencies and its changes of China- a comparative study base on DEA, sfa and index of Malmquist. Journal of Applied Statistics and Management 2014;33:878-89.

15. Xiao HX, Cao T, Tang L. Measurement and analysis of government health expenditures and health efficiency. Chinese Journal of Health Policy 2014;7:71-7.

16. Luo L, Hu M. An analysis on the productive efficiency of China's regional health and care services. Statistics \& information forum 2008;23:47-51.

17. Aigner D, Lovell CAK, Schmidt P. Formulation and estimation of stochastic frontier production function models. J Econom 1977;6:21-37.

18. Cooper WW, Seiford LM, Tone K. Data envelopment analysis: a comprehensive text with models, applications, references, and DEASolver software. Boston: Kluwer Academic Publishers, 2000.

19. Seiford LM, Thrall RM. Recent developments in DEA. J Econom 1990;46:7-38.

20. Charnes A, Cooper WW, Rhodes E. Measuring the efficiency of decision making units. Eur J Oper Res 1978;2:429-44.

21. Banker RD, Charnes A, Cooper WW. Some models for estimating technical and scale Inefficiencies in data envelopment analysis. Manage Sci 1984;30:1078-92.

22. Evans DB, Tandon A, Murray CJ, et al. Comparative efficiency of national health systems: cross national econometric analysis. BMJ 2001;323:307-10.

23. Jacobs R, Smith PC, Street A. Measuring efficiency in health care: Analytic techniques and health policy. Cambridge: Cambridge University Press, 2006.

24. Simar L, Wilson PW. Non-Parametric tests of returns to scale. Eur J Oper Res 2002;139:115-32.

25. Badunenko O, Mozharovskyi P. Nonparametric frontier analysis using Stata. Stata J 2016;16:550-89.

26. Badunenko O, Simar TH. And Wilson two-stage efficiency analysis for Stata. FAU discussion papers in economics. Friedrich-Alexander University Erlangen-Nuremberg, Institute for Economics 2018.
27. Hadad S, Hadad Y, Simon-Tuval T. Determinants of healthcare system's efficiency in OECD countries. Eur J Health Econ 2013;14:253-65.

28. de $\operatorname{Cos} \mathrm{PH}$, Moral-Benito E. Determinants of health-system efficiency: evidence from OECD countries. Int $J$ Health Care Finance Econ 2014;14:69-93.

29. Ravangard R, Hatam N, Teimourizad A, et al. Factors affecting the technical efficiency of health systems: a case study of economic cooperation organization (Eco) countries (2004-10). International Journal of Health Policy and Management 2014;3:63-9.

30. Achoki T, Hovels A, Masiye F, et al. Technical and scale efficiency in the delivery of child health services in Zambia: results from data envelopment analysis. BMJ Open 2017;7:e012321.

31. Li Y, Zeng X, Liu J, et al. Can China achieve a one-third reduction in premature mortality from non-communicable diseases by 2030 ? BMC Med 2017;15:132.

32. Merali HS, Lipsitz S, Hevelone N, et al. Audit-identified avoidable factors in maternal and perinatal deaths in low resource settings: a systematic review. BMC Pregnancy Childbirth 2014;14:280.

33. Feng $\mathrm{XL}$, Zhu J, Zhang L, et al. Socio-Economic disparities in maternal mortality in China between 1996 and 2006. BJOG: An International Journal of Obstetrics Gynaecology 2010;117:1527-36.

34. Yang S, Zhang B, Zhao J, et al. Progress on the maternal mortality ratio reduction in Wuhan, China in 2001-2012. PLoS One 2014;9:e89510.

35. Erickson P, Wilson R, Shannon II. Years of healthy life, 1995.

36. Hyder AA, Rotllant G, Morrow RH. Measuring the burden of disease: healthy life-years. Am J Public Health 1998;88:196-202.

37. Chowdhury $\mathrm{H}$, Zelenyuk V. Performance of hospital services in Ontario: DEA with truncated regression approach. Omega 2016;63:111-22.

38. Fuchs VR. More variation in use of care, more flat-of-the-curve medicine. Health Aff 2004; Variation:VAR104-7.

39. Asandului L, Roman M, Fatulescu P. The efficiency of healthcare systems in Europe: a data envelopment analysis approach. Procedia Economics and Finance 2014;10:261-8.

40. Cetin VR, Bahce $S$. Measuring the efficiency of health systems of OECD countries by data envelopment analysis. Appl Econ 2016;48:3497-507.

41. Pérez-Cárceles MC, Gómez-Gallego JC, Gómez-Gallego M Environmental factors affecting European and Central Asian healthsystems' bias-corrected efficiency. Appl Econ 2018;50:3432-40.

42. González E, Cárcaba A, Ventura J. Value efficiency analysis of health systems: does public financing play a role? J Public Health 2010;18:337-50.

43. Sun D, Ahn H, Lievens T, et al. Evaluation of the performance of national health systems in 2004-2011: an analysis of 173 countries. PLoS One 2017:12:e0173346.

44. OECD. Health at a glance 2017: OECD indicators. Pairs, 2017

45. Shain M, Roemer Ml. Hospital costs relate to the supply of beds. Mod Hosp 1959;92:71-3.

46. National Health and Family Planning Commission. China health and family planning statistical Yearbook 2016. Beijing: Peking Union Medical College Publishing House, 2016.

47. Zhang $\mathrm{H}$, Liu $\mathrm{Y}$, Yang $\mathrm{Q}$, et al. A system dynamics simulation model of hierarchical medical care system reform in China. J Health Med Inform 2017;08.

48. Wu D, Lam TP. Underuse of primary care in China: the scale, causes, and solutions. The Journal of the American Board of Family Medicine 2016;29:240-7

49. Stringhini S, Carmeli C, Jokela M et al. Socioeconomic status and the $25 \times 25$ risk factors as determinants of premature mortality: a multicohort study and meta-analysis of 1.7 million men and women. The Lancet 2017;389:1229-37.

50. Rodríguez Martín JA, Holgado Molina MdelM, Salinas Fernández JA. An index for quantifying female education and child health in emerging economies. Arch Dis Child 2015;100(Suppl 1):S10-S12.

51. Sanders LM, Federico S, Klass P, et al. Literacy and child health: a systematic review. Archives of Pediatrics \& Adolescent Medicine 2009;163:131-40.

52. Or Z, Wang J, Jamison D. International differences in the impact of doctors on health: a multilevel analysis of OECD countries. J Health Econ 2005;24:531-60.

53. Gong P, Liang S, Carlton EJ, et al. Urbanisation and health in China. The Lancet 2012;379:843-52.

54. Kinfu Y, Sawhney M, Inefficiency SM. Inefficiency, heterogeneity and spillover effects in maternal care in India: a spatial stochastic frontier analysis. BMC Health Serv Res 2015;15:118. 